\title{
Sense of Humor Dr. (HC) KH. Ahmad Hasyim Muzadi pada Acara Reuni Akbar 90 Tahun Pondok Gontor
}

\author{
Oleh : Waluyo Satrio Adji \\ Dosen UIN Maulana Mallik Ibrahim - Malang - Indonesia \\ Email: waluyo.satrio.adji@gmail.com
}

\begin{abstract}
KH. Hasyim Muzadi is a person who has the Sense of humor, this was evidenced in his lecture at the grand reunion 90 years of Pondok Gontor. Sense of humor becomes an effective method for conveying a message or value. The approach in this study uses a descriptive type qualitative approach. The data in this case is the Sense of Humor lecturer, while the source of the data is the lecture KH.Hasyim Muzadi in the grand reunion event of 90 years Pondok Gontor. The analysis used is qualitative descriptive analysis. The results in this study that the element of Sense of Humor is owned by KH Hasyim Muzadi during the lecture, the aspect of Sense of Humor used dominantly on the aspect of innuendo or criticism and aspects of a funny story. The type of Sense of Humor used is the intellectual type of humor, because of the intellectual background of the speaker.
\end{abstract}

\section{ABSTRAK}

KH. Hasyim Muzadi adalah orang yang memiliki Sense of humor, hal tersebut dibuktikan dalam ceramahnya padaa acara reuni akbar 90 tahun pondok Gontor. Sense of humor menjadi metode yang efektif untuk menyampaikan pesan atau nilai. Pendekatan dalam penelitian ini menggunakan pendekatan kualitatif jenis deskripstif. Data dalam hal ini adalah Sense of Humor penceramah, sedangkan sumber data adalah ceramah KH. Hasyim Muzadi dalam acara reuni akbar 90 tahun pondok Gontor. Analisis yang digunakan adalah analisis deskripstif kualitatif. Hasil dalam penelitian ini bahwa elemen Sense of Humor dimiliki oleh KH Hasyim Muzadi saat ceramah, aspek Sense of Humor yang digunakan dominan pada aspek sindiran atau kritikan dan aspek cerita lucu. Jenis Sense of Humor yang digunakan adalah jenis intelektual humor, karena latar belakang intelektualitas penceramah.

Kata Kunci: Sense of Humor, KH. Hasyim Muzadi, Reuni Gontor 
JURNAL PIWULANG, Vol. 2 No. 1 September 2019, 1-10

\section{A. Pendahuluan}

\section{"Ath-thoriqatu ahammu minal maddah. Wal mudarris ahammu minat thoriqah.}

"Metode lebih baik dari pada materi, sedangkan guru lebih baik dari pada metode itu sendiri". Mahfuzod dari Pondok Gontor di atas begitu terkemuka di kalangan santri pondok gontor karena didengungkan di setiap kegiatan pondok, jika berpikir kritis penanaman tersebut menandakan bahwa dalam beberapa pembelajaran penting memperhatikan aspek metode dan guru, karena berhasil atau tidaknya suatu pembelajaran tergantung dari dua aspek tersebut.

Hal tersebut benar adanya jika melihat fenomena disrupsi yang terjadi baru-baru ini pembelajaran diwarnai dengan mesin pencari dari google.com yang didalamnya terdapat mesin pencari untuk mencari materi berupa teks, gambar, video, jurnal, dsb. Materi yang banyak ternyata bukan malah menjadikan guru dan siswa, akan tetapi mengaburkan kebenaran materi itu sendiri (https://www.kompasiana.com diakses tanggal 1 September 2019).

Pada aspek metode pada jurnal yang ditulis Nasution (2017) bahwa hasil penelitiannya tentang penggunaan metode pembelajaran pada proses berpengaruh pada hasil belajar siswa. Jurnal selanjutnya yang ditulis oleh Dewi (2018) dengan hasilnya bahwa model pembelajaran konvensional dan modern sama-sama diterima dan model yang diterapkan dalam pembelajaran adalah model kooperatif dibandingkan model CTL serta model lain. Dua hasil jurnal tersebut menandakan bahwa pembelajaran wajib memperhatikan metode dalam menyampaikan pesan pendidikan.

Pembelajaran jika dimaknai secara luas tidak hanya dalam kelas atau di sekolah-sekolah tetapi pembelajaran adalah letaknya di dunia ini sampai kematian menjemput, salah satu dari pembelajaran di masyarakat adalah ceramah agama. Meskipun di luar sekolah dalam ceramah tetap memperhatikan metode sebagai alat menyampaikan pesan. Senada dengan jurnal penelitian Eka Rahayuningsih (2013), bahwa penyampaian ceramah K.H. Anwar Zahid dipadukan dengan guyonan, membuat pendegar paham tentang pesan yang disampaikan.

Pentingnya metode dalam penyampaian pesan pembelajaran begitu diperhatikan oleh para ulama dari kalangan Nahdatul Ulama, salah satunya adalah mantan ketua PBNU tahun 1999 sampai 2010, Ahmad Hasyim Muzadi atau lebih dikenal dengan nama KH. Hasyim Muzadi. Pada ceramahnya yang terdokumentasi di situs youtube.com semisal hampir menggunakan metode humor untuk menanamkan nilai kearifan hidup. Penggunaan metode bukan tanpa maksud, dilatarbelakangi dari melihat 
JURNAL PIWULANG, Vol. 2 No. 1 September 2019, 1-10

aspek sosiokultural, semisal peserta didik dengan sosiokultural masyarakat jawa yang suka bercanda dapat dipastikan lebih senang bercanda atau humor cerdas dalam menerima pesan serius.

\section{B. Pembahasan}

\section{Profil singkat KH. Hasyim Muzadi}

Nama lengkap

Tempat tanggal lahir

Jabatan Terakhir

Pekerjaan

Kebangsaan

Pasangan

Almamater

Pengalaman Organisasi

Karya Ilmiah
: Dr (Hc.) Ahmad Hasyim Muzadi,

: Tuban, 8 Agustus 1944

Meninggal di Malang, 16 Maret 2017

: Dewan Pertimbangan Presiden tahun 2015

: Pengasuh Pondok Pesantren Al-Hikam di Malang dan Depok

: Indonesia

: Hj. Muthamimah

: Institut Agama Islam Negeri Malang

: Ketua PMII

Ketua PBNU 1999-2010

1. Membangun NU Pasca Gus Dur, Grasindo, Jakarta, 1999.

2. NU di Tengah Agenda Persoalan Bangsa, Logo, Jakarta, 1999.

3. Menyembuhkan Luka NU, Jakarta, Logos, 2002.

\section{Sense of Humor KH. Hasyim Muzadi}

Humor yang dimaksud dalam penelitian ini adalah ketika penceramah menuturkan cerita kemudia direspon penonton dengan ketawa. Peristiwa kehidupan tentang kelucuan dasarnya adalah pengalaman pribadi (Sumarthana, 1983). Sense of Humor yang dimiliki penutur dalam hal ini KH.Hasyim Muzadi dapat dilihat dari anekdotanekdot yang disampaikan kepada penonton atau yang hadir di reuni akbar 90 tahun Pondok Gontor.

\section{a. Aspek sense of humor}

Aspek humor menurut Sofan (dalam indrawanto, 2008: 22) terbagi menjadi 3 yaitu (1) humor berbentuk cerita, (2) penggunaan bahasa yang tidak lazim, (3) berisi sindiran. Pada ceramah yang disampaikan KH.Hasyim Muzadi mengandung ketiga hal tersebut dengan rincian: 
JURNAL PIWULANG, Vol. 2 No. 1 September 2019, 1-10

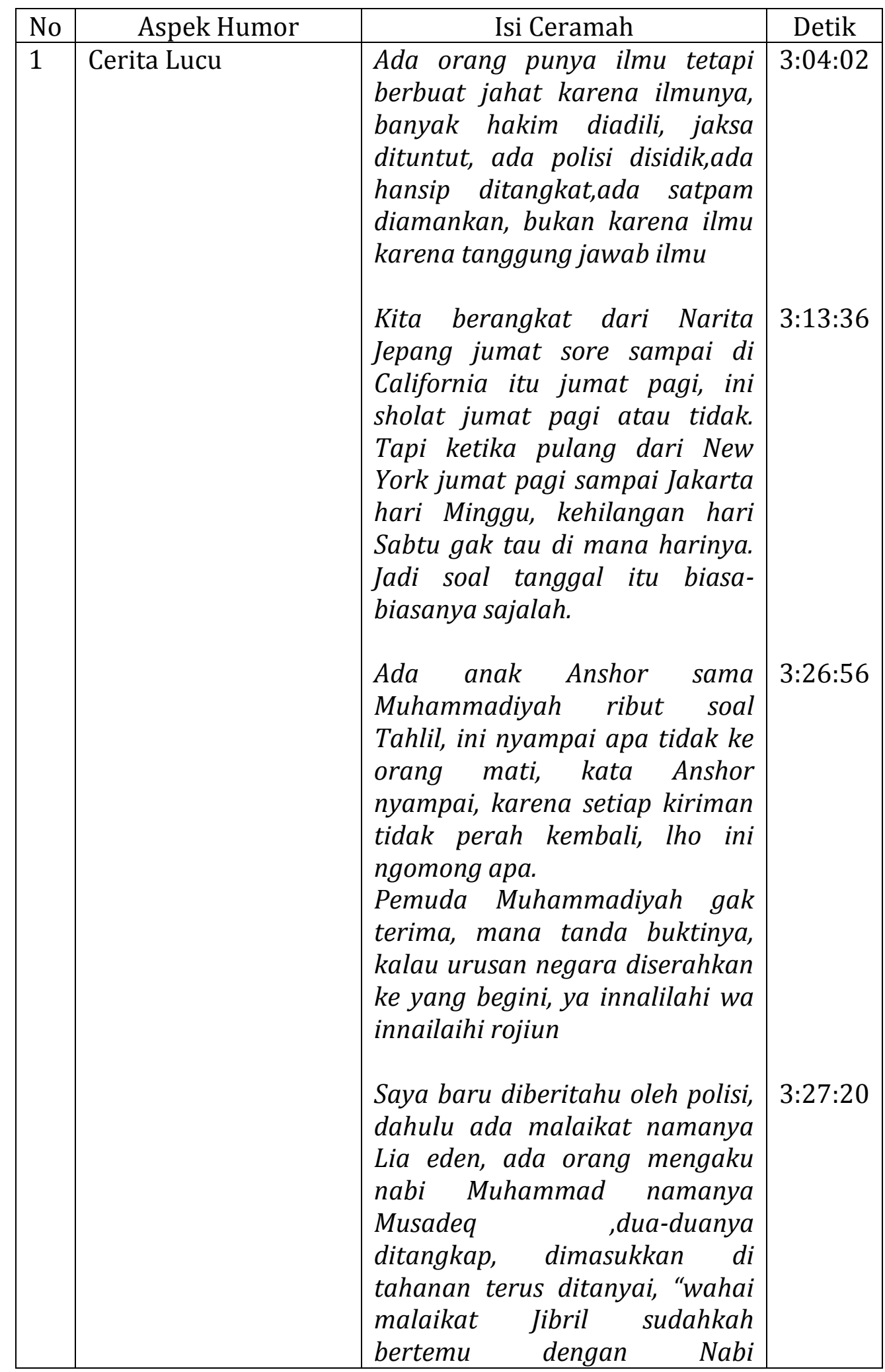


JURNAL PIWULANG, Vol. 2 No. 1 September 2019, 1-10

\begin{tabular}{|c|c|c|c|}
\hline & & $\begin{array}{l}\text { Muhammad ini, mereka } \\
\text { menjawab tidak pernah ketemu" } \\
\text { Saya beli di jalan Surabaya Pak } \\
\text { Din,itu lampu yang kuno } \\
\text { haganya mahal 2,5 jt kalau yang } \\
\text { baru } 600 \text { ribu, saya minta yang } \\
\text { kuno, saya di kasih yang baru, } \\
\text { saya bilang ke orangnya, "pak } \\
\text { ini baru,bukan kuno", orangnya } \\
\text { menjawab, "haduh sampean kok } \\
\text { rewel, ini biarkan saja nanti } \\
\text { kuno sendiri". Itu namanya } \\
\text { sekarang mukidi, akhirnya saya } \\
\text { bayar 600 ribu, orangnya } \\
\text { respon, "pak ji ini kurang", saya } \\
\text { balas,"kurangnya nanti kalau } \\
\text { sudah kuno". }\end{array}$ & $3: 41: 45$ \\
\hline 2 & $\begin{array}{ll}\text { Penggunaan } & \text { Bahasa } \\
\text { Tidak Lazim } & \end{array}$ & - & - \\
\hline 3 & Sindiran/ Kritikan & $\begin{array}{l}\text { Saya punya teman doktor, } \\
\text { doktor kan sudah paling tinggi, } \\
\text { itu kalau di kampus ditakuti } \\
\text { mahasiswa, tetapi kalau di } \\
\text { rumah dimarahi istrinya bisa } \\
\text { bodoh mendadak, } \\
\text { Ini guyon tapi bener, bahwa ilmu } \\
\text { yang di kepala akan goncang } \\
\text { ketika hatinya bergoncang } \\
\text { Kalau keluar dari gontor terus } \\
\text { diam,berarti dia bawa kunci } \\
\text { ilmu saja,itu ngapain,mungkin } \\
\text { dia tukang kunci } \\
\text { Zaman saya dahulu, masyarakat } \\
\text { Islam Cuma terbagi menjadi dua, } \\
\text { kalau gak NU yang } \\
\text { Muhammadiyah. Selisih sedikit } \\
\text { saja ribut, Soal Qunut berbeda } \\
\text { sedikit ribut, padahaldi kitabnya }\end{array}$ & $\begin{array}{l}3: 06: 07 \\
3: 09: 50\end{array}$ \\
\hline
\end{tabular}


JURNAL PIWULANG, Vol. 2 No. 1 September 2019, 1-10

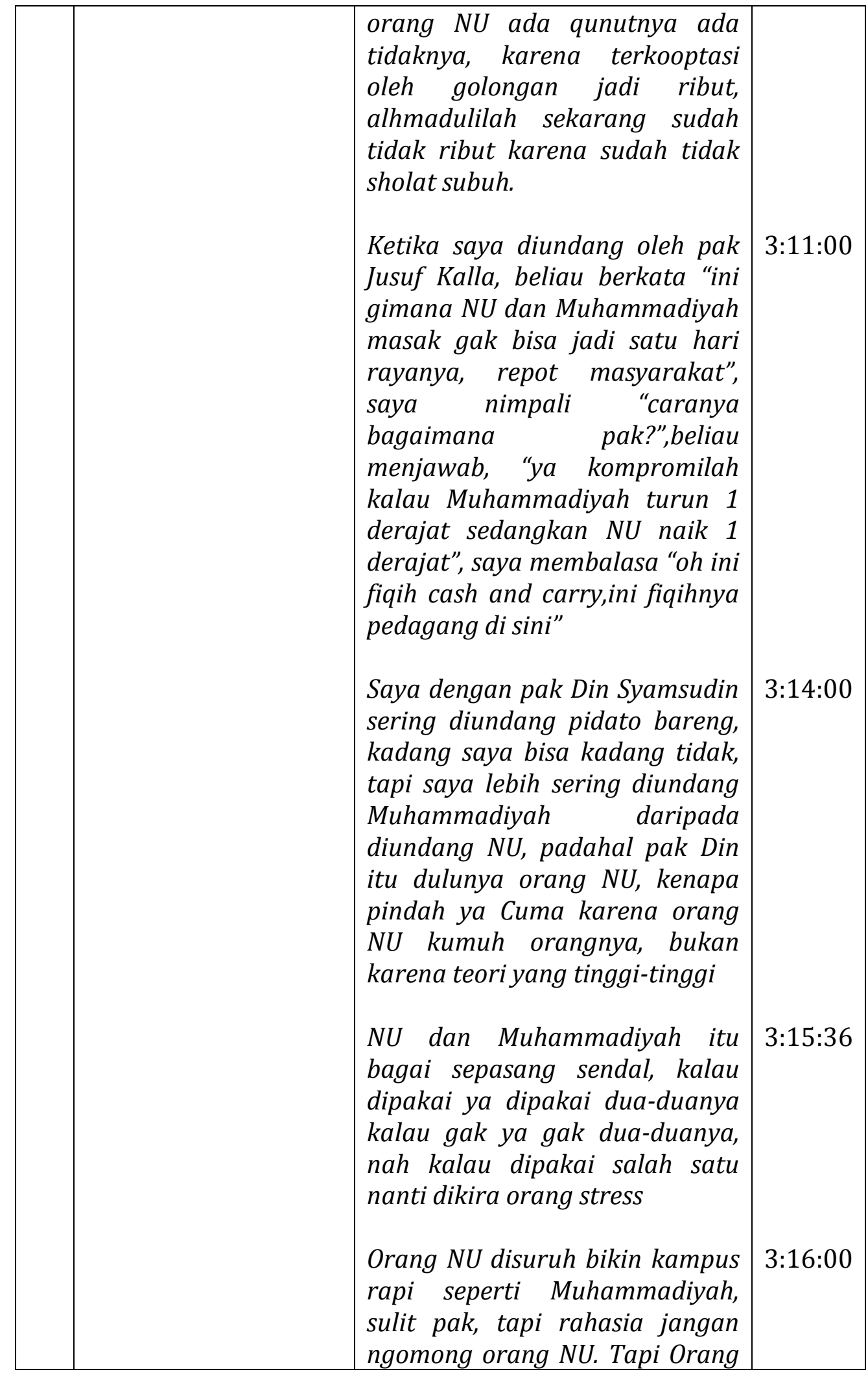


JURNAL PIWULANG, Vol. 2 No. 1 September 2019, 1-10

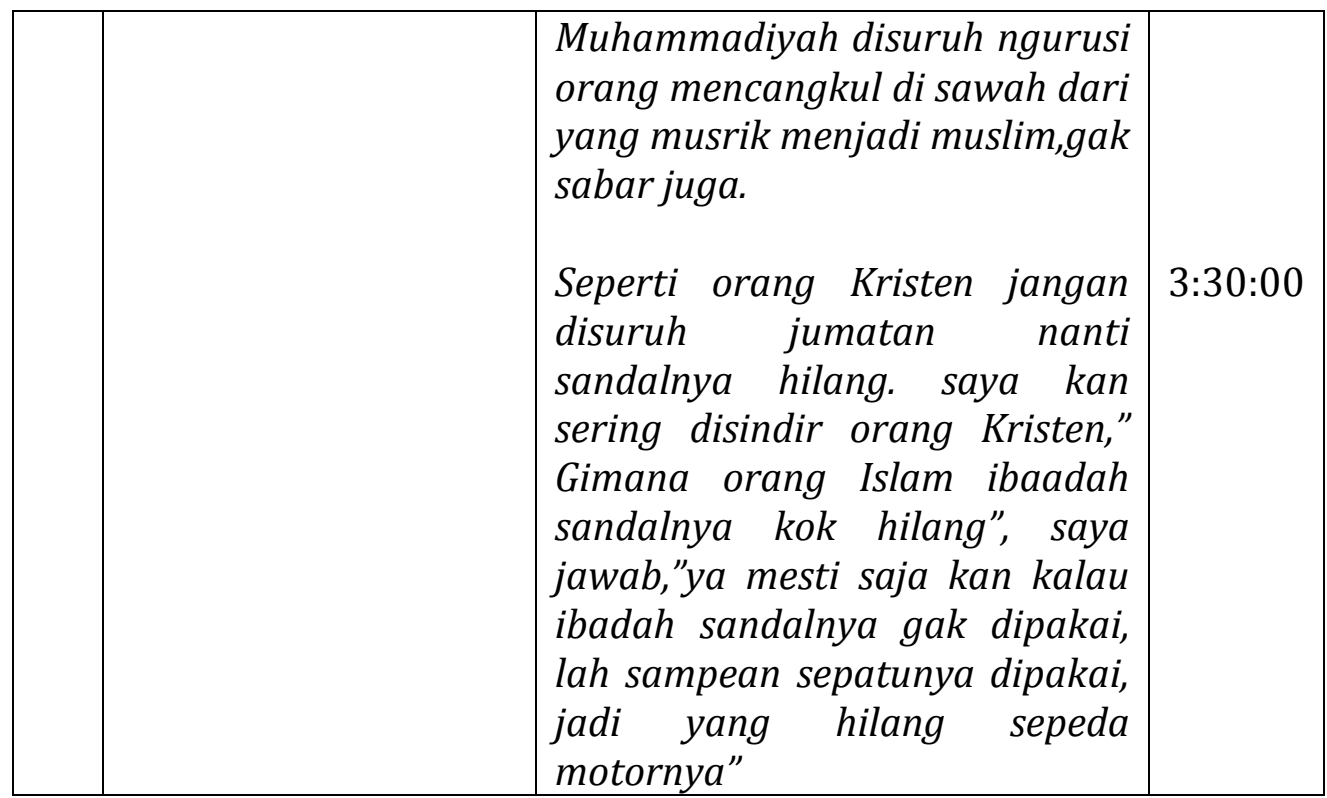

Dari perincian aspek di atas dapat dijelaskan metode humor pada aspek yang dominan berisi tentang sindiran atau kritikan terhadap bangsa Indonesia khusunya masyarakat yang hidup di negara Indonesia. Kemudian diselingi beberapa aspek cerita lucu yang tidak jauh dari latar belakang penceramah atas pengalaman semasa hidup, sedangkan tidak ada aspek bahasa yang tidak lazim,dikarenakan forumnya berada pada forum intelektual pada lembaga pendidikan juga penutur orang dengan intelektual tinggi.

Dalam video ceramah, penonton begitu banyak yang terbawa sehingga tertawa lepas mendengar ceramah yang disampaikan tetapi tetap mengikuti kaidah yang ada atau tidak lepas dari inti ceramah. Hal ini karena superioritas dari penceramah, (Munadar, 2009:80) jika melihat dari latar belakang penceramah adalah aktif di Organisasi mulai dari masa muda yaitu ketua PMII sampai masa tua menjadi ketua Pengurus Besar Nahdatul Ulama (PBNU), karena dalam organisasi terdapat kumpulan orang-orang dalam keseharian selalu bersosial bahkan belajar karakteristik sekumpulan orang. Menjadikan penceramah tahu kondisi sosial masyarakat Indonesia.

Terkait faktor mempengaruhi sense of Humor yang dikemukakan Danandja (dalam indrawanto, 2008: 20-21) dikarenakan kesenioran menjadikan penyaji menguasai dalam menyampaikan pesan-pesan keagamaan dibalut humor cerdas. Faktor lain yang membuat sukses adalah kondisi latar yaitu reuni akbar yang di atas panggung adalah tokoh-tokoh penting masyarakat Indonesia, sehingga perhatian tertuju ketika penutur menyampaikan pesan. 
b. Elemen Sense of Humor

Beberapa elemen yang dimiliki seorang penutur, dilihat dari teori yang dikemukakan Thorson dan Powell (1993) terbagi menjadi 6 yaitu:

1) Humor Production, dalam ceramah tentang sesuatu di luar Islam.

Saya baru diberitahu oleh polisi, dahulu ada malaikat namanya Lia eden, ada orang mengaku nabi Muhammad namanya Musadeq ,duaduanya ditangkap,dimasukkan di tahanan terus ditanyai, "wahai malaikat Jibril sudahkah bertemu dengan Nabi Muhammad ini, mereka menjawab tidak pernah ketemu"

Konteks di sini penceramah menghubungkan dengan jalur utama ceramah yang saat itu bercerita tentang sesuatu di luar Islam harus dinyatakan secara tegas bukan Islam, kemudian menghubungkan dengan cerita lucu nabi dan malaikat palsu.

2) Sense of Playfulness

Saat melakukan ceramah diikuti humor dalam keadaan reuni atau temu kangen orang yang pernah belajar bersama,sehingga suasana akrab diiringi dengan humor cerdas membuat suasana semakin hangat, ditambah penutur juga alumni pondok Gontor.

3) Social Use Humor

Alumni Pondok Gontor kebanyakan berada di dalam dua organisasi yaitu NU dan Muhammadiyah, dalam hal ini penutur sering menyindir kedua organisasi muslim tersebut, seperti pada ceramahnya:

Orang NU disuruh bikin kampus rapi seperti Muhammadiyah, sulit pak, tapi rahasia jangan ngomong orang NU. Tapi Orang Muhammadiyah disuruh ngurusi orang mencangkul di sawah dari yang musrik menjadi muslim, gak sabar juga.

4) Personal Recognition of Humor

Kemampuan melihat diri secara humoris, hal ini terlihat dari ceramahnya,

Ketika saya diundang oleh pak Jusuf Kalla, beliau berkata "ini gimana $N U$ dan Muhammadiyah masak gak bisa jadi satu hari rayanya, repot masyarakat", saya nimpali "caranya bagaimana pak?",beliau menjawab, "ya kompromilah kalau Muhammadiyah turun 1 derajat sedangkan NU naik 1 derajat", saya membalasa "oh ini fiqih cash and carry,ini fiqihnya pedagang di sini"

5) Appreciation of Humor

Kemampuan dalam mengapresiasi dalam situasi yang lucu, tergambar dalam ceramahnya:

Saya beli di jalan Surabaya Pak Din,itu lampu yang kuno haganya mahal 2,5 jt kalau yang baru 600 ribu, saya minta yang kuno, saya di 
kasih yang baru, saya bilang ke orangnya, "pak ini baru,bukan kuno", orangnya menjawab, "haduh sampean kok rewel, ini biarkan saja nanti kuno sendiri". Itu namanya sekarang mukidi, akhirnya saya bayar 600 ribu, orangnya respon, "pak ji ini kurang", saya balas,"kurangnya nanti kalau sudah kuno".

6) Adaptation of humor

Contoh pada adaptasi humor, terdeskripsi di ceramah beliau, Kita berangkat dari Narita Jepang jumat sore sampai di california itu jumat pagi, ini sholat jumat pagi atau tidak. Tapi ketika pulang dari new york jumat pagi sampai jakarta hari minggu, kehilangan hari sabtu gatau di mana harinya. Jadi soal tanggal itu biasa-biasanya sajalah

\section{c. Jenis Sense of Humor}

Jenis humor menurut Sarwono (dalam Novandi, 2009: 6-7) dapat dikategorikan dalam 3, meliputi: (1) Gerak (2) Intelektual (3) Jenis Gabungan yang ada dalam penelitian ini adalah humor cerdas atau intelektual. Hal tersebut tercermin dalam ceramah beraspek sindiran seperti:

"Saya punya teman doktor, doktor kan sudah paling tinggi, itu kalau di kampus ditakuti mahasiswa, tetapi kalau di rumah dimarahi istrinya bisa bodoh mendadak, Ini guyon tapi bener, bahwa ilmu yang di kepala akan goncang ketika hatinya bergoncang".

Untuk gerak, di sini tidak ada mimik untuk berdiri karena saat ceramah berlangsung penutur dalam keadaan duduk mulai awal sampai akhir. Hal tersebut dikarenakan kondisi acara bukan resmi untuk acara humor tetapi pesan-pesan baik dalam acara reuni Pondok Gontor.

\section{Kesimpulan}

Penjelasan atas pembahasan penelitian di atas dapat disimpulkan bahwa:

1. Aspek Sense of Humor yang digunakan dominan pada aspek sindiran atau kritikan dan aspek cerita lucu, sedangkan aspek bahasa yang tidak lazim tidak ada

2. Sense of Humor dimiliki oleh KH Hasyim Muzadi adalah saat ceramah sesuai dengan teori Thorson dan Powell (1993) yaitu (1) Humor Production, (2) Sense of Playfulness, (3)Social Use Humor, 
(4)Personal Recognition of Humor, (5)Appreciation of Humor, (6)Adaptation of humor.

3. Jenis Sense of Humor yang digunakan adalah jenis intelektual humor, karena latar belakang intelektualitas penceramah.

\section{Daftar Pustaka}

Gontortv. 2016. Reuni Akbar 90 tahun Pondok Gontor. https://www.youtube.com/watch?v=ETeG fQve6Q_(diakses tanggal 28 Agustus 2019)

Melynda. 2018. Beradaptasi di era disrupsi. https://www.kompasiana.com/melynda25588/5b470217ab12ae 455956c0a2/beradaptasi-dengan-era-disrupsi?page=all, (diakses tanggal 1 September 2019)

Munandar, Utami. 2009. Pengembangan kreativitas anak berbakat. Jakarta:Rineka cipta.

Nasution, Mardiah Kalsum. 2017. Penggunaan Metode Pembelajaran Dalam Peningkatan Hasil Belajar Siswa. STUDIA DIDAKTIKA: Jurnal Ilmiah Bidang Pendidikan Vol. 11, No. 1

Novandi, Nikko. 2009. Hubungan antara Rasa Humor dengan Perilaku Seksual pada Remaja. Skripsi, Fakultas Psikologi Univeritas Gunadarma Kalimalang

Nugraha, Indrawanto. 2008. Hubungan antara Efikasi Diri dan Sense of. Humor dengan Partisipasi Kerja Karyawan. Skripsi. Fakultas. Psikologi Universitas Universitas Muhammadiayah Surakarta

Rahayuningsih, dkk. 2013. Tindak Tutur Representatif Dalam Ceramah K.H. Anwar Zahid. Jurnal Pancaran, Vol. 2, No. 2, hal 105-118

Sumarthana. 1983. Anekdot-anekdot dalam Kehidupan Sehari-hari. Jakarta: Sinar Buana Press.

Thorson, J.A. and Powell, F.C. (1993) Development and Validation of a Multidimensional Sense of Humor Scale. Journal of Clinical Psychology 